\title{
O SER-ENFERMEIRO EM FACE DO CUIDADO À CRIANÇA NO PÓS- OPERATÓRIO IMEDIATO DE CIRURGIA CARDÍACA
}

\author{
The nurse-being dealing with the care to the child in the immediate post-operative \\ Cardiac surgery \\ El ser-enfermero frente a la atención al niño en el posoperativo inmediato de cirugía \\ cardíaca
}

Herwellyn Camilo de Melo ${ }^{1}$

Ana Virginia Rodrigues Veríssimo ${ }^{4}$

\author{
Sumaya Emanuelle Gomes de Araújoº \\ Estela Rodrigues Paiva Alves ${ }^{5}$
}

\author{
Victor Emmanuell Fernandes Apolônio dos Santos \\ Maria Helena Nascimento do Souza ${ }^{6}$
}

\section{RESUMO}

Objetivou-se compreender o cuidado à criança durante o pós-operatório imediato de cirurgia cardíaca a partir da percepção do ser-enfermeiro. Utilizou-se a entrevista fenomenológica com seis enfermeiras lotadas na Unidade de Recuperação de Cirurgia Torácica do Pronto-Socorro Cardiológico de Pernambuco, de março a maio de 2011. A pesquisa é de natureza qualitativa com abordagem ancorada na fenomenologia existencial de Martin Heidegger. Os dados foram produzidos e analisados de acordo com os quatro momentos propostos por Martins e Bicudo. A análise permitiu delinear o cuidado do enfermeiro como sistemático, complexo e minucioso, que requer ao mesmo tempo aptidões técnico-científicas, exigindo do ser que cuida habilidade para lidar com seus sentimentos diante das eventualidades do dia a dia. Conclui-se que o cuidado à criança é construído em meio a uma dinâmica constitutiva entre tecnologias duras e subjetividade, onde haverá momentos em que uma será valorizada em detrimento da outra.

Palavras-chave: Enfermagem pediátrica. Cirurgia torácica. Cuidados intensivos. Cuidados de enfermagem. Percepção.

\begin{abstract}
This research aimed to understand the care provided to the child during the immediate post-operative cardiac surgery according to the being-nurse's perception. The phenomenological interview was used with six nurses who work at the Thoracic Surgery Recovery Unit of Pronto-Socorro Cardiológico de Pernambuco, from March to May 2011. The research has a qualitative design and an approach based on Martin Heidegger's existential phenomenology. Data were produced and analyzed according to the four moments suggested by Martins and Bicudo. The analysis allowed delineating the nurse's care as systematic, complex and meticulous, requiring at the same time technical-scientific skills, demanding from the human being that provides care ability to tackle her feelings when facing the daily contingencies. We conclude that the care provided to the child is built with a constitutive dynamics between hard technologies and subjectivity, where there will be moments when one shall be appreciated in spite of the other.
\end{abstract}

Keywords: Pediatric Nursing. Thoracic Surgery. Intensive Care. Nursing Care. Perception.

\section{Resumen}

Esta investigación objetivó analizar la atención al niño durante el posoperativo inmediato de cirugía cardíaca desde la percepción del ser-enfermero. La entrevista fenomenológica se llevó a cabo con seis enfermeras que trabajan en la Unidad de Recuperación de Cirugía Torácica del Pronto-Socorro Cardiológico de Pernambuco, de marzo a mayo de 2011. La investigación tiene naturaleza cualitativa con abordaje anclado en la fenomenología existencial de Martin Heidegger. Los datos fueron producidos y analizados según los cuatro momentos sugeridos por Martins y Bicudo. El análisis permitió delinear la atención del enfermero como sistemática, complexa y minuciosa, que requiere al mismo tiempo aptitudes técnicas y científicas, exigiendo del ser que cuida habilidad para lidiar con sus sentimientos en las eventualidades del día a día. Se concluye que la atención al niño es construida en medio a una dinámica constitutiva entre tecnologías duras y subjetividad, donde habrá momentos en que una será valorada en detrimento de la otra.

Palabras clave: Enfermería Pediátrica. Cirugía Torácica. Atención Intensiva. Atención de Enfermería. Percepción.

\footnotetext{
${ }^{1}$ Enfermeira, graduada pela Faculdade Maurício de Nassau, Recife - PE. Brasil. E-mail: herwellyncamilo@hotmail.com; ${ }^{2}$ Enfermeira, graduada pela Faculdade Maurício de Nassau, Recife - PE. Brasil. E-mail: sumaya.emanuelle@gmail.com ; ${ }^{3}$ Enfermeiro. Especialista em Cardiologia pelo Programa de Residência em Enfermagem da Secretaria de Saúde do Estado de Pernambuco. Mestrando do Programa Associado de Pós-Graduação em Enfermagem da Universidade de Pernambuco e Universidade Estadual da Paraíba (PAPGEn-UPE/UEPB). Recife - PE. Brasil. E-mail: victoremmanuellsantos@hotmail.com; ${ }^{4}$ Enfermeira. Mestranda do Programa Associado de Pós-Graduação em Enfermagem da Universidade de Pernambuco e Universidade Estadual da Paraíba (PAPGEn-UPE/UEPB). Recife - PE. Brasil. E-mail: virginia.verissimo@gmail.com; ${ }^{5}$ Enfermeira. Mestranda do Programa Associado de Pós-Graduação em Enfermagem da Universidade de Pernambuco e Universidade Estadual da Paraíba (PAPGEn-UPE/UEPB). Recife - PE. E-mail: rodrigues.estela@gmail.com ; Enfermeira. Doutora. Professora Adjunta da Escola de Enfermagem Anna Nery da Universidade Federal do Rio de Janeiro (EEAN/UFRJ). Rio de JaneiroRJ. Brasil. E-mail: mhnsouza@yahoo.com.br
} 


\section{INTRODUÇÃO}

No Brasil, nascem por ano cerca de 6 milhões de crianças, das quais aproximadamente 45 mil são portadoras de alguma anomalia cardíaca; entretanto, a grande maioria não tem acesso a tratamento cirúrgico ou clínico, sabendo-se que $80 \%$ são portadoras de cardiopatias congênitas e necessitam ser submetidas à cirurgia cardíaca até o sexto mês de vida ${ }^{1}$.

As cardiopatias congênitas são anomalias que decorrem geralmente de uma alteração no desenvolvimento embrionário de uma determinada estrutura cardiovascular ou da incapacidade desta de se desenvolver completamente, a partir do estágio inicial do tecido fetal. A etiologia na maioria das vezes é idiopática; no entanto, sabe-se que fatores relacionados ao período do pré-natal, genéticos e ambientais estão interrelacionados com a elevação da sua incidência².

A realização do tratamento cirúrgico de crianças portadoras de cardiopatias requer uma avaliação de uma série de fatores e procedimentos realizados, que vão desde a confirmação do diagnóstico, procedimento cirúrgico, até o atendimento no pós-operatório. A complexidade que envolve a assistência à criança no pós-operatório exige a atuação de uma equipe multiprofissional com treinamento específico, cujo grande desafio consistirá em possibilitar o restabelecimento pleno da criança, com a preservação da sua integridade biopsicossocial e afetiva ${ }^{3}$.

Os cuidados de enfermagem no pós-operatório imediato podem ser definidos como cuidados prestados de forma individualizada, contínua e qualificada pela equipe durante as primeiras 24 horas após a cirurgia, tendo por objetivo proporcionar ao paciente o restabelecimento do equilíbrio hemodinâmico e ofertar condições de sobrevivência com qualidade ${ }^{3-4}$.

Nesse contexto, percebe-se que a humanização da assistência de enfermagem constitui um instrumento para o estabelecimento da integralidade, da qualidade e da segurança do cuidado prestado pela equipe. Essa humanização deve ser subsidiada em conhecimentos técnico-científicos e alicerçada em ações que venham a convergir com os princípios das crenças humanísticas ${ }^{5}$.

Desta forma, observa-se a necessidade de os profissionais de enfermagem compreenderem o processo saúde-doença pela ótica da criança e de seus familiares, haja vista que se pode desenvolver uma assistência capaz de atender as necessidades das crianças e respeitar suas singularidades, e desta forma realizar de fato um cuidado mais humanizado ${ }^{6}$.

No entanto, observa-se a escassez de relatos na literatura brasileira sobre o cuidado de enfermagem no contexto da cardiologia pediátrica, principalmente quando se trata de cuidados pós-cirúrgicos. Nesse sentido, o presente estudo busca desvelar o cuidado à criança em pós-operatório imediato de cirurgia cardíaca a partir da percepção do ser-enfermeiro, visto que o conceito de cuidar varia mediante o prisma em que é vislumbrado o ser que cuida, o ser cuidado e o cenário no qual estão inseridos ${ }^{7}$.

Diante do exposto, a pesquisa pretendida tem como objetivo compreender o cuidado à criança durante o pósoperatório imediato de cirurgia cardíaca a partir da percepção do ser-enfermeiro, tentando extrair as ideias e os sentimentos possíveis e relacionados aos eventos envolvidos nesse processo, visando substancialmente contribuir para uma prática de enfermagem no âmbito hospitalar propícia ao desenvolvimento pleno da sua saúde do ser-criança.

\section{ABORDAGEM TEÓRICO- METODOLÓGICA}

Trata-se de uma pesquisa de natureza qualitativa com abordagem ancorada na fenomenologia existencial de Martin Heidegger, uma vez que se acredita que esse ideário filosófico representa um possível horizonte a ser percorrido em prol do desvelamento pleno do fenômeno abordado a partir do relato das vivências do ser-enfermeiro ${ }^{8}$.

0 conceito de "ser" é o mais universal e o mais obscuro. A sua universalidade leva a conceituá-lo como indefinível, e diante da impossibilidade de defini-lo emerge a necessidade de compreender o seu sentido ${ }^{8}$.

Segundo Heidegger, o "ser" emana da dinâmica constitutiva do questionar e apreender; sendo assim, 0 "ser" se mostra ativo quando interroga, e as respostas a este questionamento redirecionam o objeto do questionamento para um ponto diferente do inicial. É na singularidade deste fluxo que o "ser" se desvela.

Neste contexto, a pesquisa fenomenológica permite ao pesquisador a possibilidade de imergir nos significados atribuídos aos fenômenos pelo "ser" que os experiencia em sua existência. Esse tipo de investigação é parte de uma interrogação sobre um fenômeno apresentado, e não de um problema, tendo como objetivo a descrição dos fenômenos ${ }^{8}$.

0 presente estudo foi realizado na Unidade de Recuperação de Cirurgia Torácica (URCT) Pediátrico, do hospital escola Pronto-Socorro Cardiológico Universitário de Pernambuco (PROCAPE), pertencente à Universidade de Pernambuco (UPE), situado na cidade do Recife. A referida Instituição constitui-se um dos maiores centros cardiológicos do Brasil, além de ser referência em educação e pesquisa científico-tecnológica no âmbito da Cardiologia em todo o Norte-Nordeste.

A pesquisa foi aprovada pelo Comitê de Ética em Pesquisa do Hospital Agamenon Magalhães (HAM), em 09 de dezembro de 2010, sob o protocolo de registro n 335 . Todas as participantes assinaram o Termo de Consentimento Livre e Esclarecido e concordaram com a gravação de suas falas, e, com o intuito de preservar o anonimato das mesmas, foram identificadas com pseudônimos. 
Os pseudônimos utilizados são nomes de flores, escolhidos de forma aleatória. Optou-se por citar apenas os trechos das entrevistas que elucidam de forma clara e precisa a essência do fenômeno estudado. Sendo assim, pode-se observar que, no desenvolvimento do corpo do trabalho, não foram empregadas as falas de todas as enfermeiras.

Foram entrevistadas seis enfermeiras. A captação amostral utilizou os seguintes critérios de inclusão: ser enfermeiro; estar lotado na URCT Pediátrica do PROCAPE e aceitar de livre concordância participar da pesquisa. A amostragem seguiu o critério de saturação dos dados. Este princípio determina o tamanho da amostra por meio da redundância das informações coletadas, ou seja, é realizada até o momento que não se obtém nenhuma informação nova para a pesquisa?.

Os dados foram coletados no período compreendido entre março e maio de 2011, mediante entrevista fenomenológica com as seis enfermeiras do setor, com agendamento prévio dos horários, partindo da seguinte questão orientadora: Como é vivenciado por você o cuidado à criança no pós-operatório imediato de cirurgia cardíaca?

Durante as entrevistas fenomenológicas foram lançadas expressões facilitadoras como: Fale-me um pouco mais sobre isso; explique-me um pouco mais, visando ampliar as repostas e, consequentemente, promover o desvelamento pleno do fenômeno. Tendo em vista que a formulação adequada de uma questão representa uma possibilidade de imergir no ser, e na maioria das vezes não se tem uma pergunta mais adequada no início da entrevista, ela vai se moldando no seu desdobramento através da concentração e percepção da linguagem do outro em um movimento de intuição e reflexão profunda ${ }^{10}$.

A entrevista com abordagem fenomenológica acontece sob o prisma da existência situada no encontro. 0 encontro existencial não pode ser programado, pois constitui um fenômeno que se manifesta de uma forma imprevisível. E, à medida que o entrevistador se defronta com o fenômeno, ele é obrigado a adotar uma nova postura, tendo em vista que esse encontro traz à tona a identidade do outro, fazendo com que o entrevistador reconheça que a realidade daquele ser difere da sua, levando-o a uma descentralização de si mesmo, em uma busca intencional de compreensão empática do ser que se defronta consigo ${ }^{10}$.

Nessa entrevista o entrevistador precisa deixar a situação observada e o sujeito entrevistado à margem de todos os seus modelos conceituais, projetos e valores, pois estes podem vir a direcionar um saber sobre o sujeito, e não um saber do sujeito. Desta forma, o ver e o observar são uma maneira de captar como o sujeito vivencia o mundo $^{10}$.

Na presente pesquisa, optou-se por gravar (em MP4) as entrevistas, mediante a autorização prévia das participantes, e transcrevê-las simultaneamente na íntegra para o programa Word 2007, para que nenhuma informação relevante para o estudo fosse ignorada. As entrevistas tiveram duração média de 22 minutos, sendo organizadas em uma planilha, no programa Excel 2007, na qual foram lançadas as transcrições que estavam no programa Word 2007, trabalhando-as por meio da análise fenomenológica, seguindo os quatro momentos sugeridos por Martins e Bicudo ${ }^{11}$ :

Leitura integral de cada entrevista visando uma compreensão geral do sentido do texto.

- Releitura de cada texto, quantas vezes se fizerem necessária, em busca de falas significativas que focalizem 0 fenômeno estudado dentro da perspectiva do pesquisador, as quais serão denominadas unidades de significados.

- Transformação das unidades de significados das falas do sujeito em uma linguagem do pesquisador, por meio da reflexão e imaginação, em busca dos elementos convergentes e divergentes das unidades de significados, visando encontrar os temas em comum para formação das categorias temáticas.

Síntese do pesquisador, que articula os sentidos contidos em todas as unidades de significados transformadas a uma descrição consistente das experiências do sujeito.

Os quatro momentos sugeridos pelos autores ${ }^{11}$ possibilitam à análise dos dados a luz do referencial adotado, conforme demonstra estudos semelhantes ${ }^{12}$. Desta forma, neste estudo não se utilizaram os dois momentos metódicos propostos por Heidegger em seu livro Ser e Tempo ${ }^{8}$, análise compreensiva e análise interpretativa, haja vista que nem todo estudo ancorado na fenomenologia heideggeriana contempla estes dois momentos de análises ${ }^{13}$.

\section{RESULTADOS E DISCUSSÃO}

0 cuidado de enfermagem é um fenômeno que se estrutura mediante a forma como o enfermeiro apreende a si como ser, o ser-cuidado e o contexto em que o processo do cuidar se desenvolve. Portanto, tal fenômeno não ocorre de forma simples e linear, visto que, de acordo com Heidegger, ${ }^{8} 0$ conceito de "ser" é tão universal que se torna impossível de ser definido, restando apenas a possibilidade de compreender 0 seu sentido.

Nesse contexto, pode-se dizer que a fenomenologia de Heidegger não se satisfaz apenas em ser descrição de algo que se vislumbra ao olhar, a mesma se propõe a compreender 0 sentido do texto da existência, que se elucida por meio das manifestações do $\operatorname{ser}^{14}$. Sendo assim, norteando-se por tal referencial, este estudo almejou, através da percepção do serenfermeiro, desvelar em sua essência o fenômeno em questão.

Visando ampliar a discussão dos resultados, buscou-se respaldar os achados do estudo em outros outores temáticos, pois uma vez compreendido o sentido do fenômeno para os sujeitos da pesquisa, sua essência não será alterada, mesmo que os resultados obtidos sejam subsidiados por autores que utilizem outros referenciais e métodos, conforme pode ser evidenciado em outras pesquisas ${ }^{15}$.

0 enfermeiro que atua em áreas especializadas, a exemplo da cirurgia cardiológica pediátrica, necessita 


\section{Cuidado à criança no pós-operatório cardíaco}

desenvolver estratégias para o cuidado clínico e cirúrgico embasados em conhecimentos técnico-científicos. Isso exige do profissional a sensibilidade para perceber os problemas associados à complexidade dos procedimentos cirúrgicos vivenciados pelas crianças, na fase de pós-operatório imediato, prezando pela manutenção de seu equilíbrio clínico.

As crianças portadoras de cardiopatias congênitas são geralmente pacientes crônicos, que apesar da cirurgia corretiva, necessitam de um acompanhamento clínico por toda a vida. Desta forma, torna-se necessária a ideia de fomentar durante o internamento da criança uma assistência diferenciada para que ela e sua família sintam-se acolhidas e seguras ${ }^{16}$.

Sendo assim, devido ao fato de que nem todas as malformações cardíacas são corrigidas com a cirurgia, existe a necessidade de oferecer a esses pacientes cuidados paliativos. Esses cuidados representam um conjunto de ações que visam promover uma assistência integral, pois este paciente e sua família têm necessidades especiais e requerem um cuidado diferenciado com ações articuladas, embasadas no respeito e no conhecimento de seus valores, de maneira que seja estabelecida uma relação que proporcione conforto ao ser cuidado ${ }^{17}$.

No contexto familiar, a patologia que acomete a criança faz com que a família se desestruture e também se perceba doente, pois se vê diante do risco de perda de um ente querido, além de sentir-se impotente diante das necessidades do mesmo, entre tantos efeitos que a doença acarreta no seio familiar ${ }^{17}$. A mãe passa a ver a criança como um ser completamente diferente do idealizado, questionando-se acerca de como será a sua vida, o que torna difícil para ela aceitar a malformação congênita da criança, ao mesmo tempo em que se estabelece uma relação marcada pela angústia e tristeza entre ambas ${ }^{18}$.

Desta forma, visando oferecer uma assistência diferenciada à família, a instituição onde o presente estudo foi realizado oferece, no pré-operatório, um suporte psicológico aos acompanhantes da criança, conforme demonstra a fala a seguir:

[...] lá em cima (na enfermaria) a psicóloga faz toda semana reunião com as mães, e ela conversa bastante com essas mães, até porque a maioria é congênito [...] (Acácia).

Entretanto, apesar do apoio oferecido pela referida instituição observa-se, ainda, que muitos familiares não têm estrutura emocional para acompanhar a criança após a cirurgia na unidade de terapia intensiva, visto que se fragilizam ao se depararem com a criança debilitada em um cenário tão invasivo. Este fato aponta a necessidade de se oferecer um suporte mais efetivo a esses familiares em relação ao processo cirúrgico e ao pós-operatório imediato, conforme expresso no seguinte depoimento:
[...] eu (a enfermeira) tirava umas férias na enfermaria e continuava aqui (na URCT), então eu observava muito isso, a angústia das mães na enfermaria, foi até eu que coloquei isso lá pra psicóloga, vir antes da cirurgia mostrar à mãe, porque uma mãe que nunca viu seu filho entubado, que não é da área de saúde [...] a gente que é da área de saúde quando vê algum familiar, a gente fica... né? assustado, imagina quem nunca viu [...] (Acácia).

A fala de Acácia revela que, somente quando se percebeu, desde o pré-operatório, a existência de um ser-mãe lançado ao mundo com uma criança cardiopata, é que foi possível apreender a relevância da visita pela família no cenário no qual a criança ficará após a cirurgia. A percepção do ser-com o outro também possibilita ao profissional entender aquilo que se desvela ao seu olhar; foi o que permitiu a Acácia compreender uma forma de trabalhar a fragilidade emocional da mãe, que se inicia no pós-operatório imediato.

Portanto, diante da colocação da enfermeira supracitada, a instituição adotou como conduta no préoperatório promover a visitação da criança e seus familiares à unidade de terapia intensiva. Neste setor, normalmente são as enfermeiras que recepcionam a criança e seu acompanhante, visando diminuir a angústia, o medo e o sofrimento desse binômio no pós-operatório imediato.

A equipe de enfermagem do trans e pós-operatório pode desenvolver uma excelente política de acolhimento ao fornecer à família orientações quanto às situações que podem ser vivenciadas no pré e no pós-operatório de cirurgia cardíaca, além de promover explicações a respeito da dinâmica do setor ${ }^{16}$.

A visita do binômio família-criança à unidade de terapia intensiva é elucidada na fala a seguir:

[...] nesse pré, normalmente a criança vem aqui, quando ela é maiorzinha... ela conhece a UTI... conhece o profissional que vai ficar com ela, assim, a equipe que estiver no momento se apresenta, ela conhece o ambiente [...] (Acácia).

Sendo assim, neste momento, o enfermeiro está promovendo uma assistência transversal à criança, haja vista que o seu cuidado procura atendê-la em sua dimensão biopsicossocial. Para tanto, amplia o foco da sua assistência, passando a incluir a família em seu plano de cuidados. Quando a dimensão humana do cuidar é valorizada, a prática transcende a técnica, pois ela percebe o ser em sua totalidade existencial ${ }^{17}$.

A transversalidade do cuidado das enfermeiras é exposta nos seguintes depoimentos: 
[...] a gente vê a criança toda... não é só a cirurgia cardíaca [...] (Acácia).

[...] tanto da parte clínica como da parte subjetiva, cognitiva... todo paciente que a gente tem que ver, toda essa questão também holística, que a gente não pode só olhar a patologia, mas deve olhar a criança como um todo [...] (Amarílis).

A assistência de enfermagem à criança no pós-operatório imediato é feita em equipe. Antes da admissão da criança na unidade de terapia intensiva, o enfermeiro providencia e organiza todos os insumos necessários, assim como orienta e dimensiona a sua equipe. Esta ação aprimora o desempenho da admissão e propicia uma estrutura adequada, com recursos materiais, medicamentosos, tecnológicos disponíveis para dar continuidade ao tratamento, sendo necessário também à equipe domínio e busca constante de conhecimento para um bom desempenho ${ }^{2}$.

A fala a seguir de uma das enfermeiras entrevistadas relata como se dá o gerenciamento da equipe para a admissão da criança na unidade de terapia intensiva:

\section{[...] quando o paciente está chegando, a gente já conversa com a equipe, o médico conversa com a gente: olha, a cirurgia é uma cirurgia simples... o paciente que vem é um paciente grave, provavelmente vai precisar de determinados materiais, então a gente já coordena quem vai ser responsável pelo material que for preciso, você vai ser responsável pelos drenos, a gente faz essa divisão de tarefas, basicamente. (Gardênia).}

0 enfermeiro, assim como os demais profissionais que recepcionam a criança na unidade de recuperação de cirurgia torácica, visa fazer com que a admissão ocorra com segurança e sem intercorrências, pois se trata de um paciente que foi submetido a um procedimento cirúrgico longo e agressivo, 0 qual chega ao pós-operatório imediato bastante debilitado. Além disso, embora a cirurgia tenha ocorrido com sucesso, o cuidado no pós-cirúrgico é determinante para o prognóstico.

0 pós-operatório imediato constitui um período que necessita de uma monitorização cautelosa e rigorosa, pelo fato de uma grande quantidade de cirurgias cardíacas exigir circulação extracorpórea (CEC), que desencadeia uma série de alterações nas funções fisiológicas do paciente, elevando o risco de complicações, havendo, ainda, necessidade de avaliação criteriosa das alterações apresentadas, assim como uma intervenção de forma rápida e precisa, buscando o restabelecimento das funções vitais do paciente ${ }^{4}$.

$\mathrm{Na}$ admissão da criança, os procedimentos e 0 monitoramento minucioso levam o enfermeiro a por em prática todo o seu conhecimento, valorizando a sua habilidade técnica e distanciando-se da subjetividade que envolve o cuidado.
Portanto, os primeiros cuidados do enfermeiro a essa criança são extremamente técnicos. Com isso, a subjetividade vai emergindo com a sua evolução clínica, pois até então o contexto exige do enfermeiro uma precisão técnico-científica, fazendo com que os sentimentos deste profissional, neste momento, fiquem relegados a um segundo plano.

Quando o foco da assistência é voltado para os equipamentos, os procedimentos e a doença, o cuidado perde toda a sua subjetividade, e, consequentemente, sua personalidade, além de tornar o ambiente pouco acolhedor, pois as dimensões humanas que o envolvem não adquirem seu devido destaque $\mathrm{e}^{7-17}$.

0 evento supracitado pode ser evidenciado na fala de Gardênia:

[...] quando a gente recebe a criança, que a gente toma todos os cuidados necessários, a habilidade técnica parece que é um botãozinho que a gente liga, e que a gente precisa botar o nosso conhecimento na prática, receber o paciente, estar pronto pra alguns cuidados com o paciente. $E$ a gente não sente nada momentaneamente, só quando a coisa melhora ou agrava no decorrer do tempo é que a gente vai tendo um envolvimento um pouco maior [...] (Gardênia).

No âmbito hospitalar a criança sempre estará acompanhada por um responsável, que na maioria das vezes é a mãe. Neste sentido, cuidar de uma criança significa também assistir a sua família, pois ela sofre com todo esse processo doença-saúde. E o enfermeiro, ao se deparar com a angústia, o medo e o sofrimento destes entes, deve, dentro dos limites impostos por sua formação, oferecer a eles um suporte emocional, explicando e mantendo-os cientes de tudo o que está acontecendo com a criança.

Sendo assim, pode-se dizer que a hospitalização representa para a criança e sua familia um momento de estresse, no qual emergem sentimentos e atitudes relacionados ao diagnóstico, ao tratamento e ao prognóstico da patologia. 0 enfermeiro, além de centrar seu plano de cuidados na situação clínica da criança, deve estabelecer uma comunicação com os pais ou acompanhante, uma vez que a família é fundamental para a promoção da saúde da criança ${ }^{6-17}$.

Diante deste contexto, a comunicação e o diálogo representam um processo de construção e aperfeiçoamento do âmago do indivíduo para a promoção de uma relação mais acolhedora com o outro, sendo ferramentas essenciais à sua humanização, haja vista que humanizar é uma maneira de demonstrar um comprometimento que transcende os aspectos práticos que envolvem o trabalho, atingindo outras dimensões psicossociais do ser cuidado. Esta perspectiva do cuidado representa um novo paradigma, a partir do qual o fazer e 0 pensar em saúde tornam-se duas ações que se complementam, 


\section{Cuidado à criança no pós-operatório cardíaco}

com o principal intuito de fomentar, de forma autônoma e consciente, relações de encontros e de acolhimento, nas quais a integralidade do ser cuidado seja assegurada ${ }^{2-16}$. De acordo com o que foi relatado pela enfermeira Amarílis:

\section{[...] a humanização, a meu ver, é... É a gente ter o maior carinho possível ... a delicadeza de prestar essa assistência, ... a atenção, que a gente tem à criança, aquele olhar, a gente olhar no olho, principalmente quando a criança está acordando, falar de uma maneira que não seja chocante pra ela, tem que ter aquele apport, aquele feedback, aquele carinho mesmo especial, principalmente com a mãe. Ela é consciente, tem que estar consciente de toda a situação, então a gente explicando cada passo, o que a gente está fazendo é humanizar a assistência [...] (Amarílis).}

Diante do exposto, humanizar o cuidado em uma unidade de terapia intensiva não significa negar a relevância da tecnologia que é indissociável deste cenário, mas implica valorizar e atribuir uma real importância aos aspectos relacionais ao cuidado no âmbito da saúde ${ }^{17}$. Com efeito, a predominância de uma dessas duas unidades em relação à outra dependerá da necessidade do ser cuidado e da forma como o ser-enfermeiro se vê no mundo e compreende a copresença dos outros.

\section{CONSIDERAÇÕES FINAIS}

Com o intuito de desvelar o cuidado no pós-operatório imediato de cirurgia cardíaca, tomamos como ponto de partida a imersão na fenomenologia de Martin Heidegger, para construir, enquanto fenômeno que se põe, o ser-enfermeirocom, na medida em que entendemos que esta é a forma pelo qual este percebe a si, revela-se e apreende a copresença dos outros, representando, desta forma, a plenitude da estrutura do seu cuidado.

Contudo, as falas das enfermeiras expressam que 0 cuidado da criança no pós-operatório imediato de cirurgia cardíaca está fortemente alicerçado em conhecimento técnicocientífico, devido ao avanço tecnológico, à especificidade e à minuciosidade da assistência do pós-cirúrgico cardíaco infantil. No entanto, a vulnerabilidade do ser-criança, que ainda se encontra em crescimento e desenvolvimento, em um estado de fragilidade física e emocional, desperta no ser-enfermeiro-com sentimentos e percepções fortes e por vezes conflitantes, especialmente pela contraposição entre o uso cotidiano das tecnologias duras em um ser tão carente de afeto, como a criança que é objeto de seu cuidado.

As enfermeiras, quando certas da necessidade de um cuidado integral e humanístico para as crianças sob seus cuidados, devem ampliar o foco da sua assistência, inserindo a família em seu plano de cuidado. Entretanto, neste estudo, podemos perceber que as enfermeiras percebem a família dentro da unidade não como meros coparticipantes do cuidado no pós-operatório imediato, e sim como seres cuja presença é repleta de significado e valores para a criança. Salientamos, portanto, a clara necessidade de novas pesquisas que estudem a conduta dos profissionais de saúde na perspectiva da visão destes para o potencial da inclusão da família no cuidado à criança, e os possíveis benefícios que esta prática pode trazer à humanização do cuidado. Também explicitamos a necessidade fundamental de pensar o binômio família-criança no hospital, como campo promissor de pesquisas que possam destacar 0 papel da integralidade das ações do cuidado por parte da equipe de saúde.

Continuando no campo do cuidado, desvelamos a enfermeira enquanto um ser-com que assume a responsabilidade de assegurar à criança um cuidado completo, providenciando insumos, monitorando-a constantemente, estimulando um cuidado integral. E como forma de garantir a integralidade de sua assistência, esta profissional agrega a mãe no seu cotidiano de trabalho, mediante a clara percepção de que esta requer atenção diante de suas próprias angústias ou limitações para com a assistência de seu filho doente, estando exposta a um ambiente por vezes hostil para consigo e sua prole.

0 desenrolar do cuidado ocorre em meio a uma transversalidade de ações e procedimentos que fluem de forma dinâmica e não linear entre tecnologias leves, levesduras e duras, sendo muitas vezes difícil para as enfermeiras um limite preciso entre estes universos tecnológicos. Percebemos que, no âmago do ser-enfermeiro, emerge claramente a percepção de que o cuidado prestado à criança deve ser holístico; todavia, esse profissional, diante das necessidades biológicas do paciente, que exigem o uso pronto e eficaz de procedimentos e máquinas, acaba, em certos momentos, valorando o uso das tecnologias duras em detrimentos das demais. E é nesta dinâmica estabelecida entre um limite tênue de objetividade e intersubjetividade que o enfermeiro deve estruturar o seu cuidar.

Observa-se, ainda, que esse cuidado muitas vezes torna-se silencioso e despercebido diante da assistência desenvolvidas pelos demais profissionais à criança cardiopata. Esse fato deve-se em grande parte à falta de relatos na literatura brasileira sobre o desenvolvimento de tal assistência, uma vez que o referencial teórico é fundamental para o nor teamento da prática e do ensino, e para subsidiar a elaboração de políticas públicas efetivas, assim como para o aprimoramento do cuidado, delineamento do impacto e da relevância direta desta assistência à criança cardiopata.

Diante do exposto, evidencia-se a limitação de inferência da pesquisa devido ao tamanho da população em estudo e à especificidade da temática, associados aos fatores supracitados, sendo notória a necessidade de estudos que 
abordem a enfermagem no contexto cardiológico pediátrico, para que sejam desveladas sua amplitude, dimensão e relevância no tratamento clínico e cirúrgico.

\section{REFERÊNCIAS}

1.Maluf MA, Franzoni M, Melgar E, Hernandez A, Perez R. A cirurgia cardíaca pediátrica como atividade filantrópica no país e missão humanitária no exterior. Rev Bras Cir Cardiovasc. [on-line] 2009 jul/set; [citado 2011 ago 21]; 24(3): [aprox 3 telas]. Disponível em: http://www.scielo.br.

2.Souza P, Scatolin BE, Ferreira DLM, Croti UA. A relação da equipe de enfermagem com a criança e a família em pós-operatório imediato de cardiopatias congênitas. Arq Cienc Saude [on- line] 2008 out/dez; [citado 2011 jun 11]; 15(4): 163-69. Disponível em: http:// uww.cienciasdasaude.famerp.br.

3.Batista JFC, SilvaACSS, Azeredo AN, Moura SM, Mattos VZ. A enfermagem no cuidado integrado ao recém-nascido com cardiopatia congênita cianótica: relato de caso. Online Braz J Nurs. [on- line]. 2005 abr; [citado 2010 maio 10]; 4(1). Disponível em: http://www.uff.br/objnursing/index.

4.Pileggi SO. Validação clínica do diagnóstico de enfermagem desobstrução ineficaz de vias aéreas de crianças e adolescentes submetidos à correção cirúrgica de cardiopatia congênita [dissertação]. Ribeirão Preto: Escola de Enfermagem, Universidade de São Paulo; 2007.

5.Gonzaga MLC, Arruda EM. Fontes e significados de cuidar e não cuidar em hospital pediátrico. Rev Latino-Am Enfermagem. [on- line] 1998 dez; [citado 2001 ago 21]; 6(5): [aprox 10 telas]. Disponível em: http:// www.scielo.br.

6.Moreira PL, Dupas G. Significado de saúde e de doença na percepção da criança. Rev Latino-Am Enfermagem. [on- line] 2003 nov/dez; [citado 2001 ago 21]; 11(6): [aprox 6 telas]. Disponível em: http://www.scielo.br.

7.Rocha PK, Prado ML, Wal ML, Carraro TE. Cuidado e tecnologia: aproximações através do modelo de cuidado. Rev Bras Enferm. [online] 2008 jan/fev; [citado 2011 ago 21]; 61 (1): [aprox 4 telas]. Disponível em: http://www.scielo.br.

8.Heidegger M. Ser e tempo. Tradução de Márcia de Sá Cavalcante. Petrópolis(RJ): Vozes; 1989.

9.Turato ER. Tratado da metodologia da pesquisa clínico-qualitativa: construção teórico-epistemológica discussão comparada e aplicação nas áreas da saúde e humanas. Petrópolis(RJ): Agir; 2008.

10.Carvalho AS. Metodologia da entrevista: uma abordagem fenomenológica. Rio de Janeiro: Agir; 1991.

11.Martins J, Bicudo MAV. A pesquisa qualitativa em psicologia: fundamentos e recursos básicos. São Paulo: Moraes; 1989.
12.Lanza LF. Ser-criança-com-câncer em etapa final de tratamento sua visão de futuro [dissertação]. Ribeirão Preto: Escola de Enfermagem, Universidade de São Paulo; 2008.

13.Machado AG, Padoin SMM, Paula CC, Vieira LB, Carmo DRP. Análise compreensiva dos significados de estar gestante e ter HIV/AIDS. Rev RENE. Fortaleza [on-line] 2010 abr/jun; [citado $2011 \mathrm{dez} 28$ ]; 11 (2): [aprox 7 telas]. Disponível em: http://www.revistarene.ufc.br.

14.Dartigues André. 0 que e a fenomenologia? $172^{\mathrm{a}}$ ed. São Paulo: Moraes; 1992. 325 p.

15.Padoin SMM, Terra MG, Souza IEO. Mundo da vida da mulher que tem HIV/AIDS no cotidiano da (im)possibilidade de amamentar. Esc Anna Nery. [on-line] 2011 jan/mar; [citado 2011 dez 28]; 15(1): [aprox 9 telas]. Disponível em: http://www.scielo.br.

16.Méllo DC, Rodrigues BMRD. 0 acompanhante de criança submetida à cirurgia cardíaca: contribuiç̧ão para a enfermagem. Esc Anna Nery [on- line] 2008 jun; [citado 2011 jun 11]; 12(2): [aprox 6 telas]. Disponível em: http://www.scielo.br.

17.Cunha PJC, Zagonel IPS. A relação dialógica permeando o cuidado de enfermagem em UTI pediátrica cardíaca. Rev Eletr Enferm. [online] 2006 [citado 2011 maio 25]; 8(2): 292-97. Disponível em: http://www.fen.ufg.br/revista

18.Dias IMAV, Santos RS. Os profissionais de enfermagem diante do nascimento da criança com malformação congênita. Esc Anna Nery. [on line] 2007 mar; [citado 2011 jun 11]; 11(1): [aprox 7 telas]. Disponível em: http://www.scielo.br. 